\title{
Archiv
}

f ü r

\section{wissenschaftliche Kunde}

von

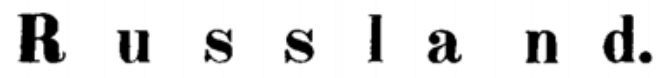

Herausgegeben

von

A. F $\mathbf{n}$ m $\mathrm{n}$ แ.

$$
\begin{aligned}
& \text { S i e b z e h n t e r } \text { B a n d. } \\
& \text { E r s t e r Inet. } \\
& \text { Mit einer Tafel. }
\end{aligned}
$$

$$
\text { B e r l i n, }
$$

Druck und Verlag von Georg Reimer.

1858. 